\title{
Carta ao editor sobre o artigo: "Avaliação radiográfica do alinhamento pós-operatório na artroplastia total de joelho" - Thomaz LDG, Geist JGB, De Lucena RDL, Schwartsmann CR, Freitas GLS, Spinelli LF. Rev Bras Ortop 2021 https://doi.org/10.1055/s-0041-1726061. (e-first)
}

\section{Letter to the Editor Regarding the Article "Radiological Evaluation of Postoperative Alignment in Total Knee Arthroplasty" - Thomaz LDG, Geist JGB, De Lucena RDL, Schwartsmann CR, Freitas GLS, Spinelli LF. Rev Bras Ortop 2021 https://doi.org/10.1055/s-0041-1726061. (e-first)} Rodrigo Sattamini Pires e Albuquerque ${ }^{1,2}$ José Leonardo Rocha de Faria ${ }^{1}$ Douglas Mello Pavão ${ }^{1 \odot}$

${ }^{1}$ Centro de Cirurgia do Joelho, Instituto Nacional de Ortopedia e Traumatologia, Rio de Janeiro, RJ, Brasil

2 Instituto Nacional de Traumatologia e Ortopedia, Faculdade de Medicina, Universidade Federal Fluminense (UFF), Niterói, RJ, Brasil

Rev Bras Ortop 2021;56(6):819-820.

\section{Caro Editor,}

Em primeiro lugar, gostaríamos de parabenizar os autores do artigo intitulado "Avaliação radiográfica do alinhamento pósoperatório na artroplastia total de joelho" ${ }^{1}$ pelo interessante artigo. Além disso, gostaríamos também de fazer alguns comentários a respeito da metodologia empregada na pesquisa.

Acreditamos que a realização das radiografias ortostáticas no pós-operatório imediato, ainda durante a internação hospitalar, pode ter comprometido a qualidade do exame de imagem, tendo em vista que a intensidade de dor e edema comuns ao pós-operatório imediato muitas vezes limita a extensão total do joelho, principalmente durante o ortostatismo.

A atitude em flexo e rotação externa do membro operado podem ter sido um viés em relação ao correto posiciona-
Endereço para correspondência Rodrigo Sattamini Pires e Albuquerque, PhD, Centro de Cirurgia do Joelho, Instituto Nacional de Ortopedia e Traumatologia, Av. Brasil, 500-Caju, Rio de Janeiro, RJ, 20940-070, Brasil (e-mail: rodalbuquerque19@gmail.com). mento do paciente e à obtenção das imagens. A realização de radiografia no pós-operatório imediato não tem se mostrado benéfica, ${ }^{2}$ e acreditamos, assim como Abu-Rajab et al., ${ }^{3}$ que a avaliação radiográfica deveria ter sido realizada em um pósoperatório mais tardio, em torno de seis semanas.

Outro ponto metodológico que julgamos inapropriado foi tentar inferir a localização da cabeça do fêmur e do centro do tornozelo na radiografia curta. Na radiografia curta, o único eixo reprodutível a ser traçado é o anatômico do fêmur e da tíbia (tibiofemoral), ${ }^{4}$ que é um bom preditor do alinhamento em longo prazo após uma artroplastial total de joelho. 4

Concluímos que, metodologicamente, as radiografias panorâmicas deveriam ter sido realizadas em um pós-operatório recebido

21 de Maio de 2021

aceito

02 de Setembro de 2021
DOI https://doi.org/

10.1055/s-0041-1736472. ISSN 0102-3616. (c) 2021. Sociedade Brasileira de Ortopedia e Traumatologia. All rights reserved.

This is an open access article published by Thieme under the terms of the Creative Commons Attribution-NonDerivative-NonCommercial-License, permitting copying and reproduction so long as the original work is given appropriate credit. Contents may not be used for commercial purposes, or adapted, remixed, transformed or built upon. (https://creativecommons.org/ licenses/by-nc-nd/4.0/)

Thieme Revinter Publicações Ltda., Rua do Matoso 170, Rio de Janeiro, RJ, CEP 20270-135, Brazil 
mais tardio, para evitar um viés de posicionamento, e que uma comparação de análises de radiografias longas e curtas só poderia ser feita levando-se em consideração o eixo anatômico tibiofemoral. Tentar inferir o eixo mecânico em uma radiografia curta causa um viés de inferência quanto à localização da cabeça do fêmur e do centro do tornozelo.

\section{Conflito de Interesses}

Os autores declaram não haver conflito de interesses.

\section{Referências}

1 Thomaz LDG, Geist JGB, De Lucena RDL, Schwartsmann CR, Freitas GLS, Spinelli LF. Avaliação radiográfica do alinhamento pós- operatório na artroplastia total de joelho. [Publicação online: 2021-04-19]. Rev Bras Ortop 2021. Disponível em: https:// www.thieme-connect.de/products/ejournals/abstract/10.1055/ s-0041-1726061

2 Niskanen RO. Early repetitive radiography is unnecessary after an uncomplicated cemented hip or knee arthroplasty for osteoarthritis. Acta Orthop Belg 2005;71(06):692-695

3 Abu-Rajab RB, Deakin AH, Kandasami M, McGlynn J, Picard F, Kinninmonth AW. Hip-Knee-Ankle Radiographs Are More Appropriate for Assessment of Post-Operative Mechanical Alignment of Total Knee Arthroplasties than Standard AP Knee Radiographs. J Arthroplasty 2015;30(04):695-700

4 Ishii Y, Ohmori G, Bechtold JE, Sherman RE, Gustilo RB. Accuracy of the short radiograph in the measurement of the tibiofemoral angle. Knee 1995;2(02):81-84 